\title{
EX VIVO STUDIES ON GLUCONEOGENESIS INHIBITORY ACTIVITY OF PIPER BETLE INFLORESCENCE
}

\author{
Sushma S. Kumar \\ Student, Department of Biochemistry, Mount Carmel College, \\ Bengaluru, Karnataka, India \\ Dr. Sowmyashree G. \\ Assistant Professor, Department of Biochemistry, Mount Carmel College, \\ Bengaluru, Karnataka India \\ Sona V. Pauly \\ Student, Department of Biochemistry, Mount Carmel College, \\ Bengaluru, Karnataka, India
}

\begin{abstract}
Piper betle leaf is known to possess various pharmacological activities like antioxidant, anti-diabetic, anti-fungal, anti-ulcer genic, antiplatelet, antiinflammatory etc. The need for this study is to extrapolate one such pharmacological activity i.e., Anti-diabetic activity to the inflorescence. Stress is one of the major factors for the onset of diabetes, a metabolic disorder that is one of the primary threats to human health. The prominent adverse side effects of the conventional drugs used for the treatment of diabetes has led to extensive research on development of natural and semi-synthetic drug molecules. In the present study, assays indicated the presence of antioxidant activity. The ex vivo studies were carried out on hepatocytes to study its role on gluconeogenesis in comparison with the betel leaf extract. The results showed that the sample extract was efficient in reducing glucose synthesis. The MTT assay proves that the sample extract is not toxic to cells at volumes of 10-50 $\mu$ l. The results of the present study indicates that the crude extract of Piper betle inflorescence is efficient in inhibiting Gluconeogenesis
\end{abstract}

Keywords - Piper betle inflorescence, Gluconeogenesis, Cortisol, Diabetes, Hepatocytes, $\alpha$ - Amylase, Lipase

\section{INTRODUCTION}

Diabetes mellitus is a metabolic disorder characterized by hyperglycaemia, glycosuria and negative nitrogen balance. This is mainly due to the absolute deficiency or diminished effectiveness of insulin, a hormone that is required to regulate the blood sugar levels. It is very prevalent disease in the world affecting $25 \%$ of the population and afflicts about 150 million people and is predicted to rise to 300 million by 2025 .
Diabetes is yet not completely curable using the present antidiabetic therapy. Insulin therapy is gaining popularity and seems to be the only satisfactory approach in diabetes mellitus, even though it comes with many of its own drawbacks like insulin resistance, anorexia, brain atrophy, and fatty liver in cases of chronic treatment. Mondal et al. (2012)

Type 2 diabetes is a primary threats to human health due to its increasing prevalence, chronic course and disabling complications. Various therapeutic strategies for the treatment of Type 2 diabetes are currently in use. The conventional therapies available in the control of diabetes include the stimulation of endogenous insulin secretion or enhancement of the action of insulin at the target tissues or oral hypoglycaemic agents such as biguanids and sulfonylureas or the inhibition of degradation of dietary starch by glycosidase such as $\alpha$-amylase and $\alpha$-glucosidase. Sudha $P$ et al. 2011

Many conventional drugs that are already used in the treatment of Diabetes Mellitus have been reported for their inefficiency with prominent adverse side effects. These limitations have led to the exploration of management strategies involving the use of medicinal plants which are reported to be cost effective anti-diabetic agents with fewer reported side effects. Sagbo et al. 2018

Stressors such as anxiety, fear, pain, haemorrhage, infection, low blood glucose and starvation stimulates the release of the corticosteroid hormone Cortisol from the adrenal cortex. The body produces other hormones such as adrenaline (epinephrine) and norepinephrine and releases them in response to these stressors, one such hormone is Cortisol. It is a steroid hormone belonging to a broader class of hormones 
known as the glucocorticoids. Cortisol affects the carbohydrate, protein and lipid metabolism. Cortisol also acts on muscles, liver tissue and adipose tissue in order to fuel the organism with to withstand stress. In liver, gluconeogenesis is promoted by Cortisol and also the stimulation of synthesis of the key enzyme Phosphoenol Pyruvate Carboxykinase (PEPCarboxykinase). The glucose thus produced is either stored in the liver in the form of glycogen or immediately exported to tissues that require glucose as fuel. The net effect of all the metabolic changes is to restore the levels of glucose in blood to normal and to maintain the levels of glycogen store which might later be used to support the flight or fight response associated with stress. The effects of insulin is counterbalanced by Cortisol. Cortisol loses it positive adaptive value in extended times of stress and starts causing damage to muscle and bone also impairing the endocrine and immune systems. Cox and Nelson. 2010

Prolonged elevated level of Cortisol is one of the causes for type $2 \mathrm{DM}$ and Insulin resistance. Stress has been suspected for a long time now to have effects in the development of diabetes as it is most often seen in people who experience significant stress. The blood sugar levels rises in order to supply energy for fight or flight on the bodies under stress physical, mental or emotional. This may also alter the flight or fight response in individuals having diabetes. The two factors responsible are, firstly, the body cells develops resistance to insulin if they do not need the extra glucose in the form of energy that floods the blood stream in response to stress hormones. Secondly, the pancreas become fatigued as insulin resistance builds and pancreas try to produce adequate amounts of insulin to nourish the cells. High cortisol levels is due to the activation of hypothalamic-pituitary-adrenal axis, due to psychological reactions to various stresses. Cortisol antagonises reaction of insulin. An increase in visceral adiposity is also seen which plays an important role by contributing to insulin resistance. Bjorntop. 1991

The term ex vivo in Latin means "out of living". The experiment is carried out outside the body of the organism by providing similar conditions in a laboratory. Living cells or tissues are dissected from an organism and cultured in sterile laboratory apparatus with almost no alterations of the physiological conditions for up to 24 hours in order to attain adequate number of cells to conduct the experiment. Tissues can be retrieved in several ways including as a whole organ, a part of the organ or the entire organ system. The advantage of ex vivo tissue is the capability in performing tests that would otherwise not be practicable due the one main reason of ethical issues to perform in living organisms.

Stress is considered to be an important case for Type 2 Diabetes Mellitus. The body under stress is known to increase glucose production via gluconeogenesis in order to meet the energy demands for fight and flight. This demand is elevated during stress. The stress hormone - Cortisol so produced antagonises insulin action leading to insulin resistance. Bjorntop. 1991

\section{MATERIALS AND METHOD}

\section{A. Source of plant material \\ Leaves and Inflorescence of Piper betle were collected locally and used for the preparation of extracts. The present study was conducted at Mount Carmel College, Bangalore}

\section{B. Preparation of sample extracts}

$4.5 \mathrm{~g}$ of the fresh inflorescence sample was weighed and transferred into a mortar containing methanol (30ml), this was then homogenized thoroughly and incubated with continuous stirring in a magnetic stirrer for 1 hour at room temperature. The mixture was then transferred into centrifuge tubes and centrifuged at 10,000 rpm for 5 minutes at room temperature. After centrifugation, the supernatant was filtered to make sure the extract was clear. The $15 \%$ methanol extract of Piper betle inflorescence was stored in an air tight container at $4{ }^{\circ} \mathrm{C}$.

$2.5 \mathrm{~g}$ of the dry powdered leaf sample was weighed and transferred to a beaker containing $60 \%$ ethanol $(50 \mathrm{ml})$, the was then incubate with continuous stirring in a magnetic stirrer for 1 hour at room temperature. The mixture was then transferred into centrifuge tubes and centrifuged at 10,000 rpm for 5 minutes at room temperature. After centrifugation, the supernatant was filtered to make sure the extract was clear. The 5\% ethanol extract of Piper betle leaf was stored in an air tight container at $4^{\circ} \mathrm{C}$.

\section{Extraction of Peroxidase enzyme and Ammonium Sulphate precipitation of the crude enzyme extract}

White radish roots were collected from local market, washed, minced and homogenized with $0.1 \mathrm{M}$ phosphate buffer $\mathrm{pH}$ (7.0) in the ration $1: 1$ in a motor and pestle, then the homogenate was filtered and centrifuged for 3000rpm for 5 min at $4^{\circ} \mathrm{C}$. The supernatant was collected after centrifugation and stored at $-20^{\circ} \mathrm{C}$ until use. The total protein content and the enzyme activity of the extract was determined. Abbas and Sabbah. 2010. The amount of protein in the crude enzyme extract was determined by Lowry's method using BSA $(100 \mu \mathrm{g} / \mathrm{ml})$ as standard.

$60 \%$ ammonium sulphate was added to the crude extract with constant stirring. The solution was centrifuged at $4000 \mathrm{rpm}$ for 20 minutes at $4^{\circ} \mathrm{C}$. The supernatant containing the peroxidase enzyme was collected and stored at $-20^{\circ} \mathrm{C}$ until use. Abbas and Sabbah. 2010. The activity of the extracted peroxidase enzyme was determined. Gorel et al. 2017

\section{Determination of Antioxidant activity}

$10-50 \mu \mathrm{l}$ aliquots of standard Gallic acid $(100 \mu \mathrm{g} / \mathrm{ml})$ was pipetted out into different test tubes. The volumes in each tube 
was made up to $100 \mu \mathrm{l}$ using distilled water. $0.5 \mathrm{ml}$ of $1 \%$ potassium ferricyanide was added to all the tubes followed by incubation for 15-20 minutes at room temperature. After incubation, $0.5 \mathrm{ml}$ of $10 \%$ TCA was added to all the tubes followed by $0.1 \mathrm{ml}$ of $0.1 \% \mathrm{FeCl}_{3}$. All the tubes were made up with $4.0 \mathrm{ml}$ of distilled water and absorbance was read at 700 $\mathrm{nm}$ in a colorimeter. The antioxidant content in the extracts was expressed as $\mathrm{mg}$ equivalents of Gallic acid in $\mathrm{mg} / \mathrm{ml}$ of extract.

DPPH radical scavenging assay was carried out using Ascorbic acid $(200 \mu \mathrm{g} / \mathrm{ml})$ ass standard. 200-1000 $\mu \mathrm{l}$ aliquots of standard Ascorbic acid was pipetted out into different test tubes. The volumes in each tube was made up to $1000 \mu \mathrm{l}$ with distilled water. The blank was devoid of the standard and contained only $1000 \mu \mathrm{l}$ of distilled water. $3.0 \mathrm{ml}$ of DPPH $(20 \mu \mathrm{g} / \mathrm{ml})$ was added to this mixture. The reaction mixture was then incubated in dark at room temperature for 10 minutes and the absorbance was read at $517 \mathrm{~nm}$ in a spectrophotometer. The DPPH radical scavenging effect was calculated in percentage using the following formula: JianHua Xie et al. 2010

DPPH radical scavenging effect $(\%)=$

Absorbance of DPPH - Absorbance of sample $\times 100$

\section{Absorbance of DPPH}

\section{E. Determination of role on Gluconeogenesis}

The liver of Gallus gallus domesticus was locally obtained and washed using normal saline and the kept immersed in saline until use. The liver cells are viable for 6 hours this under this condition and the entire study was carried out within 4 hours Olinga and Schuppan. 2013. Cortisol $(2 \mathrm{mg} / \mathrm{ml})$ was obtained from Jain Hospital, Miller's road, Vasanthnagar, Bengaluru. 5 $\mu \mathrm{l}$ was use in with liver tissue. Hems et al. 1966

Glucose release was studied using modifications with Glucose ( $\mu \mathrm{g} / \mu \mathrm{l}$ solution) as substrate, Glucose oxidase $\left(10^{5} \mu \mathrm{g} / 250 \mu \mathrm{l}\right)$. $0.1 \mathrm{M}$ phosphate buffer $\mathrm{pH} 7.0$ and Guaiacol $(5 \% \mathrm{v} / \mathrm{v})$ as chromogen. The reaction was carried out in time intervals of 30 seconds. The absorbance of the coloured complex was read at $420 \mathrm{~nm}$ in a spectrophotometer. $20-100 \mu \mathrm{g} / \mu \mathrm{l}$ aliquots of glucose was pipetted out in to different eppendorf tubes and made up to $100 \mu \mathrm{l}$ with $0.1 \mathrm{M}$ phosphate buffer $\mathrm{pH}$ 7.0. Add $10 \mu \mathrm{l}$ of glucose oxidase to all the tubes and incubate at room temperature for 10 minutes. Add $10 \mu \mathrm{l}$ of the peroxidase enzyme to all the tubes and incubate at room temperature for 5 minutes. Add $10 \mu \mathrm{l}$ of the chromogen Guaiacol to all the tubes and make up the volume to $1.0 \mathrm{ml}$ with phosphate buffer. The coloured complex formed was read at $420 \mathrm{~nm}$ in a spectrophotometer. Abbas and Sabbah. 2010

Gluconeogenesis was studied indirectly by studying the glucose released using glucose oxidase reagent. Hems et al. 1966

The standard mixtures were prepared as follows:

a) Liver + PBS - to $250 \mathrm{mg}$ of liver tissue in a cell culture plate, $2 \mathrm{ml}$ of PBS was added and the basal glucose release by the liver tissue was estimated at 15 minute intervals from 0 to 120 minutes.

b) Liver + PBS + Cortisol - to $250 \mathrm{mg}$ of the liver in a cell culture plate, $1 \mathrm{ml}$ of PBS was added followed by the addition of $5 \mu \mathrm{l}$ of Cortisol. The glucose released by the liver tissue was estimated at 15 minute intervals from 0 to 120 minutes.

c) Liver + PBS + Sodium pyruvate - to $250 \mathrm{mg}$ of the liver in a cell culture plate, $1 \mathrm{ml}$ of PBS was added followed by the addition of $100 \mu$ of Sodium pyruvate $(20 \mu \mathrm{g} / \mathrm{ml})$. The glucose released by the liver tissue was estimated at 15 minute intervals from 0 to 120 minutes.

d) Liver + PBS + Cortisol + Sodium pyruvate - to $250 \mathrm{mg}$ of the liver in a cell culture plate, $1 \mathrm{ml}$ of PBS was added followed by the addition of $5 \mu \mathrm{l}$ of Cortisol and $100 \mu \mathrm{l}$ of Sodium pyruvate $(20 \mu \mathrm{g} / \mathrm{ml})$. The glucose released by the liver tissue was estimated at 15 minute intervals from 0 to 120 minutes.

$10 \mu \mathrm{l}$ of the reaction mixture was taken into a 96 well micro titre plate and the volume was made up to $50 \mu$ with Millipore water. $30 \mu \mathrm{l}$ of Glucose oxidase $\left(10^{5} \mu \mathrm{g} / 250 \mu \mathrm{l}\right)$ was added followed by $20 \mu \mathrm{l}$ of $0.1 \mathrm{M}$ phosphate buffer $\mathrm{pH} 7.0$ and the reaction mixture was incubated for 10 minutes at room temperature. $10 \mu \mathrm{l}$ of Peroxidase was added followed by the addition of $10 \mu \mathrm{l}$ of Guaiacol and $250 \mu \mathrm{l}$ of phosphate buffer. The colour developed was read at $420 \mathrm{~nm}$ in an ELISA reader. Ex vivo studies were carried out to determine the reduction in cortisol activity by the sample extracts and the effects were compared to the standard.

Effects on glucose release by the hepatocytes was studied by adding $1.0 \mathrm{ml}$ of the sample extracts to cell culture plates containing $250 \mathrm{mg}$ of liver tissue, $100 \mu \mathrm{l}$ of PBS and $5 \mu \mathrm{l}$ of Cortisol. The glucose released was estimated at 15 minute intervals from 0 to 120 minutes. $10 \mu \mathrm{l}$ of the reaction mixture was taken into 96 well micro titre plates and the volume made up to $50 \mu \mathrm{l}$ with Millipore water. $30 \mu \mathrm{l}$ of Glucose oxidase was added followed by $20 \mu$ lof $0.1 \mathrm{M}$ phosphate buffer $\mathrm{pH} 7.0$ and the reaction mixture was incubated for 10 minutes at room temperature. After incubation, $10 \mu \mathrm{l}$ of Peroxidase was added followed by the addition of $10 \mu \mathrm{l}$ of Guaiacol and $250 \mu \mathrm{l}$ of phosphate buffer. The colour developed was read at $420 \mathrm{~nm}$ in an ELISA reader.

Effects on Gluconeogenesis was studied by adding $1.0 \mathrm{ml}$ of the sample extracts to cell culture plates containing $250 \mathrm{mg}$ of liver tissue, $100 \mu \mathrm{l}$ of PBS, $5 \mu \mathrm{l}$ of Cortisol and $100 \mu \mathrm{l}$ of Sodium pyruvate. The glucose released was estimated at 15 minute intervals from 0 to 120 minutes. $10 \mu \mathrm{l}$ of the reaction mixture was taken into 96 well micro titre plates and the volume made up to $50 \mu \mathrm{l}$ with Millipore water. $30 \mu \mathrm{l}$ of Glucose oxidase was added followed by $20 \mu \mathrm{l}$ of $0.1 \mathrm{M}$ phosphate buffer $\mathrm{pH} 7.0$ and the reaction mixture was incubated for 10 minutes at room temperature. After incubation, $10 \mu \mathrm{l}$ of Peroxidase was added followed by the 
addition of $10 \mu \mathrm{l}$ of Guaiacol and $250 \mu \mathrm{l}$ of phosphate buffer. The colour developed was read at $420 \mathrm{~nm}$ in an ELISA reader.

\section{F. Toxicity study}

MTT assay was performed to check cell viability and cytotoxicity. $0.25 \mathrm{~g}$ of liver tissue was placed in cell culture plates and $1.0 \mathrm{ml}$ of DMEM medium containing $0.1 \%$ of Pen/Strep was added to each well. 10, 20, 30, 40 and 50 $\mu$ of sample extracts were added except in the control well. The cell culture plates were incubated at $37^{\circ} \mathrm{C}$ for 24 hours. After incubation, $20 \mu \mathrm{l}$ of MTT $(0.5 \mathrm{mg} / \mathrm{ml})$ was added to each well and incubated for 4 hours. The reaction stopped by the addition of $1.0 \mathrm{ml}$ of $0.04 \mathrm{~N} \mathrm{HCl}$ in isopropanol and the reaction mixture was centrifuged at $3000 \mathrm{rpm}$ for 10 minutes to pellet out any cells from the mixture. Absorbance of the supernatant was read at $570 \mathrm{~nm}$ in a spectrophotometer. MacRae et al. 2003

\section{RESULTS AND DISCUSSION}

The enzyme, Peroxidase was extracted from white radish roots and the total protein in the crude enzyme extract was found to be $8.73 \mathrm{mg} / \mathrm{ml}$. the crude extract was then partially purified and the Peroxidase enzyme activity was determined to be positive.

The antioxidant content in terms of Gallic acid equivalence and the DPPH radical scavenging activity of $15 \%$ methanolic extract of fresh Piper betle Inflorescence and 5\% ethanolic extract of the dry powdered Piper betle leaf was investigated and the results are shown in Table 1 and 2. The sample extracts were found to be having good antioxidant property with the ethanolic extract have having a high DPPH radical scavenging activity of $92.0 \pm 0.68 \%$ while the methanolic extract was found to contain $0.39 \pm 0.05 \mathrm{mg} / \mathrm{ml}$ Gallic acid equivalence.

Effects on glucose release by hepatocytes and effects on Gluconeogenesis in the presence of the sample extracts was plotted as a function of time in comparison with a standard devoid of the sample extracts as shown in Figure 1 and 2. The glucose released by cortisol induced chicken hepatocytes on treatment with $15 \%$ methanolic extract of fresh Piper betle Inflorescence was seen to increase in the first hour and then decrease in the second with a maximum at 60 minutes when compared to the glucose released by cortisol induced chicken hepatocytes on treatment with $5 \%$ ethanolic extract of the dry powdered Piper betle leaf. Gluconeogenesis was seen to decrease with time on treatment of the hepatocytes with $15 \%$ methanolic extract of fresh Piper betle Inflorescence and 5\% ethanolic extract of the dry powdered Piper betle leaf. The methanolic extract was seen to show a greater decrease in Gluconeogenesis when compared to the ethanolic extract.

The sample extracts were not found to be toxic at volumes of $10,20,30,40$ and $50 \mu \mathrm{l}$ after it was incubated with hepatocytes for a duration of 24 hours.
Table 1: The antioxidant content of $15 \%$ methanolic extract of fresh Piper betle Inflorescence and 5\% ethanolic extract of the dry powdered Piper betle leaf expressed in terms of Gallic acid equivalence

\begin{tabular}{|c|c|c|c|c|}
\hline Sample extracts & $\begin{array}{c}\text { Trial } \\
\text { 15\% methanolic }\end{array}$ & $\begin{array}{c}\text { Trial } \\
2\end{array}$ & $\begin{array}{c}\text { Trial } \\
3\end{array}$ & $\begin{array}{c}\text { Amount } \\
(\mathrm{mg} / \mathrm{ml})\end{array}$ \\
$\begin{array}{c}\text { extract - } \\
\text { Inflorescence }\end{array}$ & 0.350 & 0.375 & 0.445 & $\begin{array}{c}0.39 \pm \\
0.05\end{array}$ \\
\hline $\begin{array}{c}5 \% \text { ethanolic extract } \\
\text { - Leaf }\end{array}$ & 0.125 & 0.445 & 0.445 & $\begin{array}{c} \\
0.34 \pm\end{array}$ \\
\hline
\end{tabular}

Table 2: The DPPH radical scavenging activity of $15 \%$ methanolic extract of fresh Piper betle Inflorescence and $5 \%$ ethanolic extract of the dry powdered Piper betle leaf expressed as percentage

\begin{tabular}{|c|c|c|c|c|}
\hline Sample extracts & 1 & 2 & 3 & $\begin{array}{c}\% \\
\text { Trial } \\
\text { effect }\end{array}$ \\
\hline $\begin{array}{c}\text { 15\% methanolic } \\
\text { extract - }\end{array}$ & & & & $\begin{array}{c}\text { Trial } \\
\text { scavenging }\end{array}$ \\
$\begin{array}{c}\text { Inflorescence } \\
\text { 5\% ethanolic extract } \\
\text { - Leaf }\end{array}$ & 81.9 & 86.8 & 88.1 & 3.26 \\
\hline
\end{tabular}

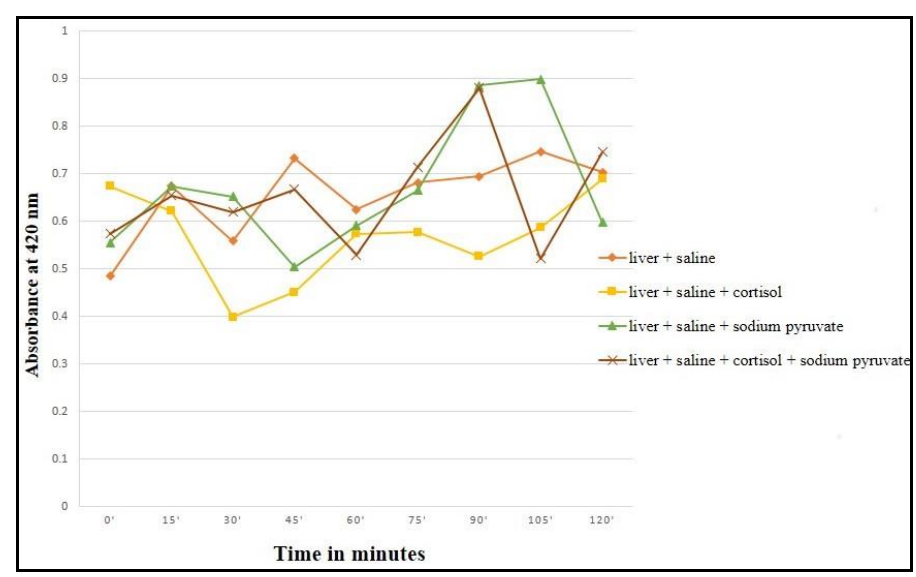

Figure 1: Standards for the study of Gluconeogenesis by indirectly studying the glucose release (values are expressed as mean $\pm \mathrm{SD}, \mathrm{n}=3$ ) 


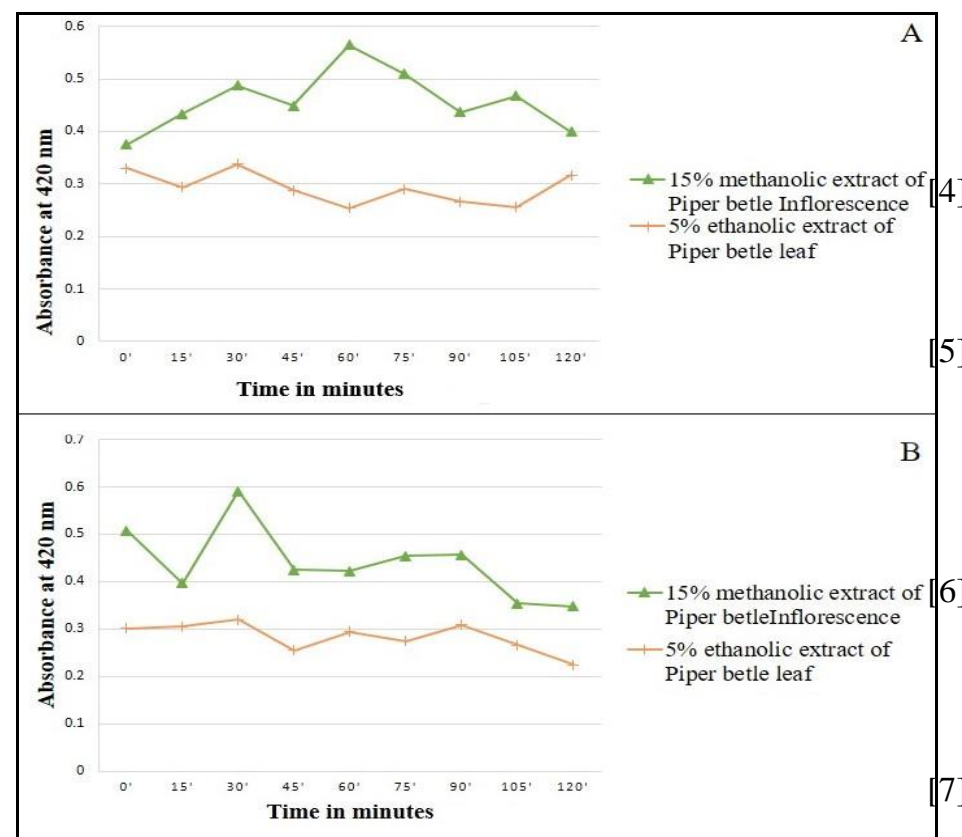

Figure 2: Effects on glucose release by Cortisol induced hepatocytes and effects on Gluconeogenesis in the presence of the sample extracts plotted as a function of time

\section{CONCLUSION}

The results of the present study indicate that Piper betle Inflorescence extract has a rich antioxidant property and is effective in reducing the glucose released by Cortisol induced hepatocytes. Gluconeogenesis is one of the important metabolic pathway directed to encounter stress. When the hepatocytes are subjected to stress with the addition of Cortisol, they tend to produce more glucose to meet the energy requirements to combat stress conditions. This is not a very favourable outcome in case of Diabetic patients. Ex vivo studies show a reduction in glucose release when compared to Cortisol and Sodium pyruvate induced Gluconeogenesis in hepatocytes as positive control. Studies focusing on the metabolites responsible for such an effect can lead to the development of an antidiabetic therapy.

\section{REFERENCE}

[1] Ayat Adnan Abbas and Majeed Arsheed Sabbah. (2017) Partial purification of peroxidase from Iraqi radish roots. International Journal of Advanced Research. (2665-2668)

[2] Bjorntop P. (1991). Diabetes Care. (1132-1143)

[3] Dr. Suneeti Gore, Dr. Arika Kotha, Dhanashree Nevgi and Juhi Shah. (2017) The Use of Horse
Radish Peroxidase, an Eco-Friendly Method for Removal of Phenol from Industrial Effluent. IOSR Journal of Environmental Science, Toxicology and Food Technology. (07-13)

4] Idowu Jonas Sagbo, Maryna van de Venter, Trevor Koekemoer and Graeme Bradley. (2018) In Vitro Antidiabetic Activity and Mechanism of Action of Brachylaena elliptica (Thunb.) DC. Research Article.

[5] Jian-HuaXie, Ming-YongXie, Shao-PingNie, MingYueShen, Yuan-XingWang, ChangLi. (2010) Isolation, chemical composition and antioxidant activities of a water-soluble polysaccharide from Cyclocarya paliurus (Batal.) Iljinskaja. Food Chemistry. (1626-1632)

6] Julia W. MacRae, Sunil S. Tholpady, Adam J. Katz, Thomas G. Gampper, David B. Drake, Roy C. Ogle, Raymond F. Morgan. (2003) Human Adipocyte Viability Testing: A New Assay Aesthetic Surgery Journal. (265-269)

17] Michael M Cox and David L Nelson. (2010) Lehninger, Principles of Biochemistry, (823)

[8] Peter Olinga and Deltef Schuppan. (2013) Precision cut liver slices: A tool to model the liver ex vivo. Journal of Hepatology. (1252-1253)

[9] R. Hems, B. D. Ross, M. N. Berry, and H. A. Krebs. (1966) Gluconeogenesis in the perfused rat liver. Biochemical Journal. (248-292)

[10] Sudha P, Smita S Zinjarde, Shobha Y Bhargava and Ameeta R Kumar. (2011) Potent $\alpha$-amylase inhibitory activity of Indian Ayurvedic medicinal plants. BMC Complementary and Alternative Medicine.

[11] Suvankar Mondal, Sanjib Bhattacharya and Moulisha Biswas. (2012) Antidiabetic activity of Areca catechu leaf extracts against streptozotocin induced diabetic rats. Journal of Advanced Pharmacy Education \& Research. (10-17)

[12] U S Jijith and S Jayakumari. (2017) Recent Advances and Methods for In vitro Evaluation of Anti-diabetic activity - A review. International Journal of Research in Ayuerveda and Pharmacy.

\section{ACKNOWLEDGEMENT}

The contributions of the Head of the Institution and the management of Mount Carmel College, Autonomous, the guidance and support of the Head of the Department of Biochemistry and all the Faculties of the Department of Biochemistry, Mount Carmel College, Autonomous. The support from our Families and Friends is deeply acknowledged. 